\title{
Trayectorias identitarias de los trabajadores de la Siderúrgica Lázaro Cárdenas Las Truchas, Michoacán
}

\author{
ELEOCADIO MARTÍNEZ SILVA
}

Se reflexiona sobre las trayectorias identitarias de los empleados de la Siderúrgica Lázaro Cárdenas Las Truchas que experimentaron el proceso de modernización de la empresa durante 1991 y 1992. Se presentan resultados de investigación en el marco de las transformaciones productivas que han operado en la industria siderúrgica, producto del desmantelamiento del Estado de Bienestar, la liberalización y la globalización económica. El propósito es coadyuvar desde la experiencia de México a la reflexión de las identidades obreras que algunos autores latinoamericanos han llevado a cabo en torno a este tema en el contexto de la intensificación del proceso de flexibilización en México. El objetivo es revisar las identidades sociológicas con base en la experiencia de la clase trabajadora en México.

PalABRAS CLAVE: reestructuración industrial, enclave, industria siderúrgica, obreros, trayectoria identitaria

Trajectories of Identity of the Workers in the Iron and Steel Industry Lázaro Cárdenas Las Truchas, Michoacán

We considered experiences about identity trajectories of the Siderúrgica Lázaro Cárdenas Las Truchas workers who lived the firm's modernization process in the years 1991-1992. Research results are presented in the context of economic globalization, commerce liberalization and loosing role of welfare state. Some Latin American authors have constructed a new sociology about the impact in the identities and subjectivities in the context of flexibility of work. The purpose of this paper is to have an insight about sociology identities regarding the experience of Mexico working class.

Eleocadio Martínez Silva Facultad de Filosofía y Letras, Universidad Autónoma de Nuevo León, Monterrey, Nuevo León eleocadio14@gmail.com
KEYWORDS: industrial restructuring, enclave, steel industry, workers, identity trajectories 


\section{Introducción}

\section{$\mathrm{H}$}

an transcurrido poco más de 20 años desde la reestructuración y la privatización de la Siderúrgica Lázaro Cárdenas Las Truchas (Sicartsa). El proceso, además de implicar el despido de la mitad de los empleados, cuestionó la significación del trabajo y de una forma de vida con la que se habían socializado los trabajadores siderúrgicos. El presente estudio centra la mirada en las identidades obreras en el enclave siderúrgico de Lázaro Cárdenas, Michoacán. Se reflexiona desde la sociología acerca de los cambios y continuidades en la identidad de los trabajadores despedidos y los sobrevivientes al proceso de modernización y privatización de la empresa ocurrido en 1991 y 1992. En el entendido de que un sector de los despedidos retornó al mundo obrero y otro no, me pregunto: ¿qué ocurrió con las identidades de los extrabajadores siderúrgicos?, ¿cuáles fueron los componentes que dibujaron, perfilaron y diferenciaron las identidades obreras? Además, dado que la identidad del trabajador de esta rama se ha transformado a partir de los cambios en la gestión de la mano de obra en la empresa, me cuestiono acerca de las características que tiene hoy en día la identidad del trabajador del acero: ¿qué significa ser empleado siderúrgico en la actualidad?, ¿hay una pérdida de las identidades obreras por la fragmentación a la que fueron sometidos?

El estudio se sustenta en el supuesto de que las características de reestructuración de Sicartsa y de la estructura económica y social del enclave siderúrgico reconfiguraron las identidades del mundo obrero. Se redefinió el "ellos" y el "nosotros", por tanto, la (re)configuración de las identidades obreras. En este proceso unos buscaron desprenderse de valores y formas de pensar construidos en la fábrica, mientras que otros hicieron uso de ellos en su (re)inserción en el mundo del trabajo. Sin embargo, la reconfiguración no significó la destrucción de las identidades. La relevancia de este trabajo radica en que amplía el entendimiento social de personas y colectivos envueltos en procesos de cambio en un ambiente social que altera su vida cotidiana, y posibilita la reflexión acerca de la vida de los obreros en ambientes de 
desempleo e inestabilidad laboral en un contexto de cambio económico y productivo.

El valor heurístico de este trabajo se relaciona con la particularidad del objeto de estudio en el sentido contextual y subjetivo-biográfico, en la medida en que las trayectorias identitarias son comprendidas por sus determinantes del contexto social, económico y cultural, y por las características individuales de quienes experimentan el suceso de despido - cultura, historia de vida, expectativas, recursos, entre otros- El trabajo de campo se realizó 20 años después de la experiencia de reestructuración industrial, básicamente durante el primer semestre de 2012. Se hicieron alrededor de 40 entrevistas a profundidad, se usó información estadística secundaria, hemerográfica y bibliográfica, así como trabajo etnográfico.

\section{Estrategia teórico-metodológica}

El tratamiento teórico-metodológico de la investigación parte del reconocimiento de la plasticidad y la consistencia de las identidades obreras, de la existencia de una identidad compartida como colectivo obrero y de una identidad fragmentada. Se da a los trabajadores un tratamiento homogéneo debido a que compartieron una misma experiencia de trabajo y reestructuración: formaron parte de una misma cohorte que con luchas sindicales logró construir una identidad colectiva, experimentaron un mismo evento de reconversión industrial y conformaron sus vidas laborales en el contexto social y económico de un enclave siderúrgico. Estos posicionamientos son relevantes para comprender lo que identitariamente vincula y separa a este sector del proletariado, permiten entender los elementos de integración en función de la clase social, así como los elementos de fragmentación de las identidades vinculados al gremio, las relaciones contractuales o categoría ocupacional de los trabajadores.

\section{Las identidades de los trabajadores: entre la integración y la fragmentación}

La reflexión acerca de la integración-fragmentación de las identidades está en el centro del debate sociológico. La perspectiva integradora de la identidad se coloca en uno de los ejes centrales de la teoría funcionalista (Parsons, 1968), en la que la identidad es inseparable de la socialización y de su eficacia. La identidad encarna el principio de unidad de las orientaciones normativas más allá de la diversidad de roles. Entre más compleja y dinámica es la sociedad más se concibe el proceso de identificación como un elemento central del orden social. A la perspectiva integradora de las identidades se opuso una fragmentada, que se encuentra principalmente en la obra del interaccionismo simbólico de Goffman (1993), que postula que la identidad no es analizada como un producto estable del sistema social y cultural, como se hace en la teoría funcionalista, sino como un proceso de negociación que los individuos establecen en el curso de las interacciones cotidianas. Tal proceso de negociación es lo que le otorga el carácter "efímero" y "múltiple" a las identidades.

Según Reygadas (1998), los aportes conceptuales de la propuesta interaccionista para el estudio de la realidad social pusieron a la investigación de las identidades en riesgo de caer en la fragmentación, ya que pierden de vista las características integradoras. Con esta perspectiva entraron en escena la heterogeneidad, los factores contextuales y la contingencia en la investigación. El resultado del debate integración-fragmentación de las identidades fue un reconocimiento de la plasticidad y la consistencia de las identidades. En esta dirección, François Dubet (1989) sostiene que los actores comparten las diferentes identidades - como integración, como recurso estratégico para la acción y de conviccióncompromiso - con diversos grados de intensidad, ya que el actor se construye en varios niveles de 
la práctica, de los cuales cada uno tiene su propia lógica y remite a tipos específicos de relaciones sociales. En la misma línea analítica, Claude Dubar (1998) concibe la identidad social en una construcción permanente a través de la relación que establece el sujeto consigo mismo y con los otros y entre las identidades heredadas y las pretendidas. Ambas transacciones se insertan en los contextos en los que los sujetos se desarrollan en el transcurso de sus vidas. Esta perspectiva sobre la identidad es muy novedosa en cuanto al reconocimiento que hace de lo complejo del proceso comunicativo que se construye desde los individuos en contextos sociales e históricamente situados.

En este debate acerca de las identidades el presente trabajo asume el posicionamiento propuesto por los sociólogos franceses Dubar y Dubet por su capacidad de variación, reacomodamiento y modulación interna, lo cual permite observar las identidades de los obreros como un proceso activo y complejo, históricamente situado y resultante de conflictos y luchas. Ofrece un marco interpretativo que posibilita vincular las experiencias pasadas, presentes y futuras de los exempleados de la siderúrgica. Metodológicamente el estudio se construye a partir de la perspectiva del curso de vida (Giele y Elder, 1998), en el entendido de que las trayectorias identitarias de estos trabajadores no han transcurrido en un vacío histórico sino en condiciones estructurales e institucionales particulares, que son el trasfondo que las determina. Desde el enfoque de los cursos de vida las trayectorias identitarias obreras son una acumulación de eventos y vivencias laborales que tienen como punto de partida la entrada a la fábrica y que se complejizan a partir de múltiples sucesos que acontecen durante la vida obrera. Estas experiencias están permeadas por la edad, la escolaridad, el género y la posición en la fábrica. La perspectiva de los cursos de vida posibilita la comprensión de las vidas de los obreros en sus contextos históricos y enlaza tiempos distintos: el individual, el familiar, el colectivo y el histórico. En los cursos de vida "trayectorias" y "transiciones" son conceptos centrales porque representan la visión de corto y largo plazo en el enfoque analítico. La utilización de este enfoque permitió a través de las entrevistas reconstruir las identidades de los trabajadores siderúrgicos de Lázaro Cárdenas con base en tres eventos importantes: el inicio de la vida en la siderúrgica, la privatización-despido y el reinicio en la vida laboral. Se trabajó con una muestra cualitativa para tener una máxima variabilidad de trabajadores entrevistados en función de la edad, la escolaridad y la posición dentro de la fábrica. Se llevaron a cabo entrevistas sucesivas hasta lograr una saturación en las dimensiones conceptuales del estudio. Se elaboraron familias de códigos para el tratamiento de la información, lo que permitió reconstruir y relacionar eventos y experiencias de los trabajadores entrevistados.

\section{Sicartsa y la comunidad obrera de enclave que ésta formó}

En concordancia con otras regiones del mundo, el enclave industrial en México fue una de las estrategias implementadas por los liderazgos nacionales para impulsar la industrialización y desarrollo regional del país. Según Francisco Zapata (1978) este tipo de propuesta obedeció a dos racionalidades: desde lo sectorial-nacional se planteaba que el país requería acero, minerales, energía eléctrica y petroquímica para sustituir las importaciones; desde lo regional se deseaba propiciar la diversificación de actividades en una zona de bajo desarrollo. Éste fue el caso de Lázaro Cárdenas, Michoacán. A principios de la década de 1960 el gobierno federal inició el ambicioso proyecto siderúrgico en la región de la costa michoacana, en el oeste de la desembocadura del río Balsas. La región experimentó grandes transformaciones en lo económico, lo político y lo social debido a la construcción de una importante infraestructura 
industrial destinada a la producción metalmecánica, petroquímica y a la actividad portuaria.

Antes de detonarse el proyecto siderúrgico, la región de Lázaro Cárdenas era una de las menos desarrolladas del país. ${ }^{1}$ El atraso fue superado parcialmente a través del reparto agrario entre 1936 y 1950. Esta medida estimuló el crecimiento poblacional y coadyuvó a superar su tradicional aislamiento (Hiernaux-Nicolas, 1986). ${ }^{2}$ El proyecto siderúrgico comenzó con la construcción de la Presa La Villita entre 1964 y 1968, lo que dio pie a la vida urbana en la región. Pocos años después, de 1973 a 1976, se construyó la siderúrgica. ${ }^{3}$ La construcción de la infraestructura que requería el enclave industrial, la misma edificación y la operación del complejo industrial estimularon la llegada de miles de personas. En la construcción de la siderúrgica se emplearon alrededor de 18000 obreros, por lo que en pocos años la población de Lázaro Cárdenas experimentó un crecimiento exponencial. ${ }^{4}$ Muchos de estos nuevos pobladores procedían en primer lugar de Michoacán y en segundo sitio de estados como Guerrero, Hidalgo, Nuevo León y la ciudad de México (Bizberg, 1982).

El proyecto siderúrgico ocasionó un desequilibrio en las estructuras económicas y sociales de la región. Para Ilán Bizberg (1982) en el proyecto industrial se ignoraron los problemas económicos y sociales de la zona: imperó la dinámica interna de la siderúrgica y se olvidó el desarrollo industrial y social local. Según el autor, en lugar de un polo de desarrollo, se generó un enclave industrial en la medida en que Sicartsa no estaba integrada a la economía regional sino a la nacional. Esta situación propició que la empresa fuera el principal actor institucional en la vida económica y social en la región. Entre las décadas de 1970 y 1980 Lázaro Cárdenas se había consolidado como un enclave industrial. Se conformó un bloque metalmecánico impulsado por la siderúrgica. Sicartsa I producía varilla y alambrón, y Sicartsa II, planchón y lámina. En la rama de bienes de capital inició operaciones el grupo integrado por Nacional Financiera (Nafinsa), Kobbe y Siderúrgica Mexicana (Sidermex), conocido como NKs, y la Productora Mexicana de Tubería (PMT) en la fabricación de tubería de gran dimensión. El empuje de la región hizo posible también la ubicación de Fertilizantes Mexicanos (Fertimex), un depósito de Petróleos Mexicanos (Pemex), un gasoducto, almacenes de la Compañía Nacional de Subsistencias Populares (Conasupo), así como pequeñas y medianas empresas. La decisión de los liderazgos nacionales de iniciar el Programa de Puertos Industriales para desarrollar y consolidar la infraestructura portuaria redefinió la identidad de Lázaro Cárdenas en la década de 1980. Entonces la ciudad adquirió una identidad de "puerto industrial", que conserva hasta la actualidad (Martínez, 2003).

\section{LA COMUNIDAD OBRERA DE ENCLAVE}

Como se mencionó, en Lázaro Cárdenas no hubo un brote protoindustrial, las identidades obreras se

1 Lázaro Cárdenas no tuvo un desarrollo protoindustrial. La riqueza mineral de la región era conocida desde tiempos prehispánicos. Sin embargo, no fue explotada durante la primera mitad del siglo xx por los concesionarios de las minas ya que el interés era aprovecharlos a futuro en el marco de una estrategia mundial sobre el uso de materias primas por las potencias industrializadas (Hiernaux-Nicolas, 1986).

2 Para 1940 la región era demográficamente insignificante. Lázaro Cárdenas tenía una población de 392 personas, Las Guacamayas de 221, La Mira de 142, Playa Azul de 237 y El Habillal de 142. La economía de la región se basaba en la agricultura de subsistencia y mantenía una baja comunicación con el resto del estado y del país (Zapata, 1978).

3 En una primera etapa la planta se enfocó a la producción de laminados no planos: varilla corrugada, barras, perfiles livianos, alambrón, etcétera. En la segunda etapa sumó a la producción laminados planos, como plancha y lámina para la industria de la transformación.

$4 \quad$ En 1970 Lázaro Cárdenas contaba con 24319 habitantes; en 1980, con 62355; en 1990, con 136699 y en 2000 con 171100 (INEGI, 2010). 


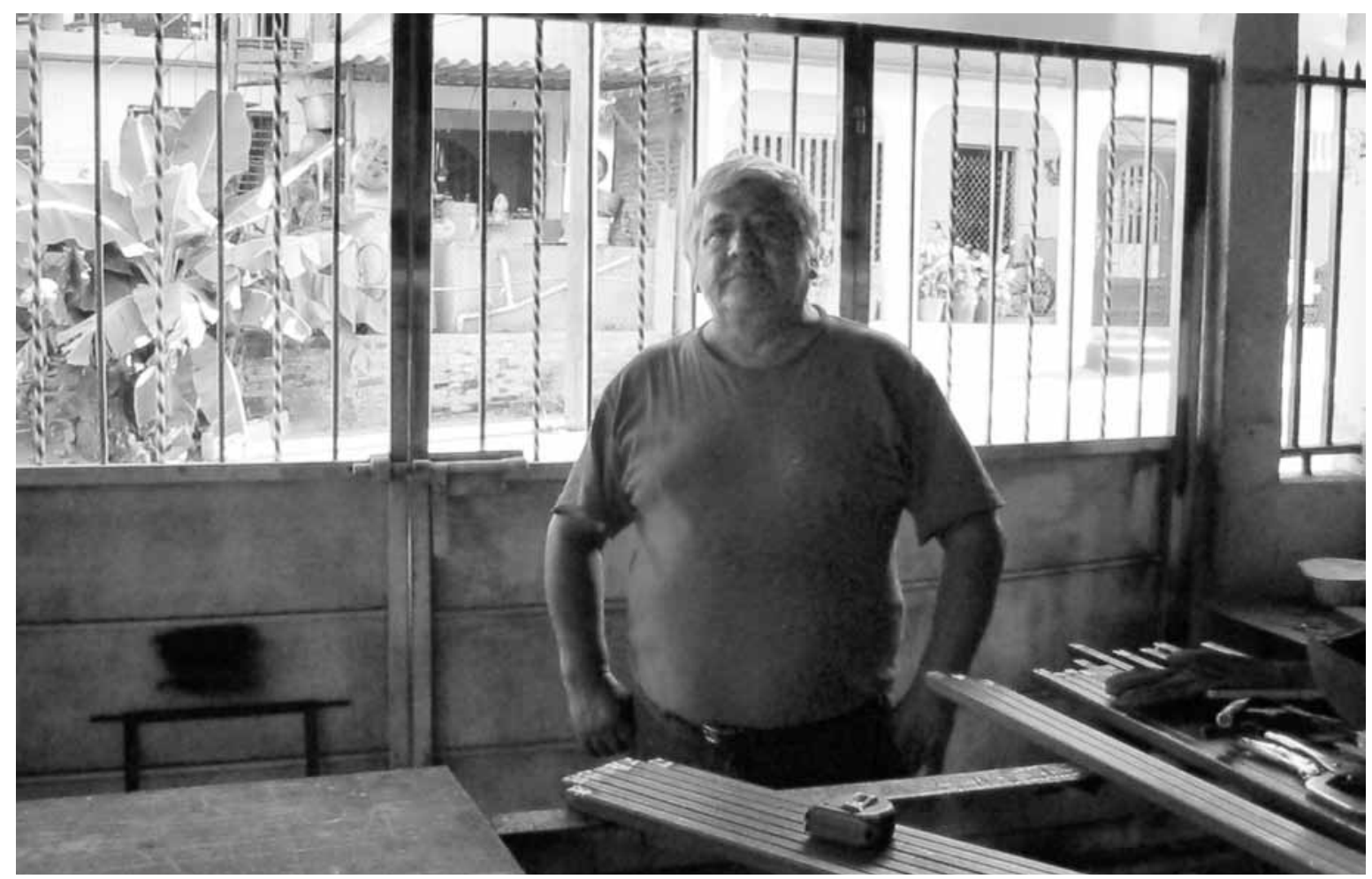

Eleocadio Martínez Silva • Exobrero Francisco

conformaron a partir del proyecto siderúrgico hacia la década de 1970. Con la operación de Sicartsa se detonó la formación de una clase obrera muy poderosa que se diferenció y eclipsó a otros sectores sociales, como los pescadores y estibadores. ${ }^{5}$ Desde sus orígenes, los trabajadores del acero han mantenido componentes homogéneos y heterogéneos en cuanto a su composición como clase. Los componentes homogéneos se formaron a partir de la Ley Federal del Trabajo (LFT), en la cual se establecieron los derechos colectivos y el trabajo protegido para los trabajadores. Con base en la LFT los empleados de la siderúrgica llevaron a cabo una acción sindical por el control del proceso productivo y el mejoramiento de las condiciones laborales, la cual se expresó en los contratos colectivos de trabajo. Desde un principio, estos obreros lograron extender sus derechos laborales, a través de diferentes episodios de conflicto obrero-patronal. Dicha extensión de derechos fue posible gracias a la acción del sindicato legitimada en el marco legal de relaciones laborales vigente en el país, ${ }^{6}$ que se extendió hasta fechas recientes, como lo muestra la gran huelga de 141 días en 2006 y la de un mes en 2009 (Reforma, 2006; Esverri, 2009).

El sindicalismo, con su discurso y su práctica ideológica, contribuyó a marcar claros procesos de diferenciación. La acción colectiva generada a

La identidad de los estibadores se construyó hace 35 años. Los primeros combinaban su trabajo con la agricultura y la pesca, debido a la poca actividad portuaria.

6 El lector podrá consultar la acción sindical de los trabajadores de Sicartsa en las obras de Bizberg y Zapata incluidas en la bibliografía. Estos trabajadores formaron el Sindicato de Estibadores de la Confederación Regional de Obreros Mexicanos (СROM) cuando se constituyó Servicios Portuarios en Lázaro Cárdenas. 
partir de la estructura de poder sindical transformó de manera importante la vida colectiva en la comunidad, en el sentido de facilitar que los trabajadores se reconocieran como grupo y como sujetos de derechos, lo que favoreció la formación de una identidad colectiva. A la identidad patronal de una "gran familia acero" de control benévolo se antepuso una con un nítido sentido de clase, un "nosotros" y un "ellos" bien definidos en la medida en que se constituyó como un poder que enfrentaba al de los patrones. La condición de enclave también contribuyó a la cohesión de los trabajadores. Según Bizberg (1982), el aislamiento del enclave del resto del sistema nacional, al requerir de una categoría obrera con cierto grado de calificación, llevó a los trabajadores a construir una organización sindical muy combativa. Además, las condiciones urbanas hostiles que enfrentaban los obreros en los enclaves llegaron a ser un factor importante de cohesión.

Otro rasgo de la homogeneidad obrera fue su composición como clase. Dice Bizberg (1982) que en Sicartsa había una proporción elevada de obreros con grados de calificación. Predominaban aquellos con experiencia en trabajo industrial o que podían adquirir rápidamente las habilidades para el trabajo en las acereras, en tanto el componente heterogéneo de la clase obrera siderúrgica se debe, según este autor, a la gran estratificación dentro de la estructura ocupacional de la planta. Tal estratificación existía en función de una serie de características obreras, como el origen rural-urbano, la historia ocupacional, el nivel de escolaridad, el grado de integración al sistema de trabajo industrial y la calificación. En ese sentido, si bien había homogeneidad relativa en el grupo obrero que trabajaba en la siderúrgica, la alta jerarquización de esta rama industrial la contrarrestaba, lo que constituye el factor preponderante de división (Bizberg, 1982). Bizberg vincula la jerarquización del trabajo a los problemas que enfrentaban y a sus condiciones laborales. De ahí que el obrero más calificado, con un oficio, una personalidad profesional, mayor nivel de escolaridad, una posición más elevada dentro de la industria y privilegios en su situación de trabajo y salarial se preocupara más por la defensa de su personalidad profesional que por cuestiones meramente económicas, mientras que obreros menos calificados en vías de integración al sistema de trabajo industrial tendían a interesarse en alcanzar mejores salarios y prestaciones económicas, además de darle una gran importancia a la seguridad del empleo.

\section{Inflexión en el enclave siderúrgico de Lázaro Cárdenas}

Como en el resto de América Latina, desde inicios de la década de 1980 en México se implementaron acciones para transformar el modelo de desarrollo imperante de sustitución de importaciones. Una de las medidas consistió en la privatización de la empresa pública. Las consecuencias inmediatas del cambio de rumbo se reflejaron en la liquidación de la Fundidora de Monterrey en mayo de 1986, en los procesos de reestructuración de empresas como Minera de Cananea en 1989, Altos Hornos de México (AHMSA) y Sicartsa de 1990 a 1991, en el cierre de la refinería petrolera de Azcapotzalco en 1991 y en la liquidación de Luz y Fuerza del Centro en 2009. Como corolario de este proceso de cambio de modelo en el sector siderúrgico el holding acerero en México quedó compuesto por AHMSA, de capital privado nacional (Grupo Acerero del Norte); Sicartsa, que finalmente pertenece al capital hindú agrupado en el grupo ArcelorMittal; Tubos de México, que fue adquirida por capital italiano, y Hojalata y Lámina, que pasó a ser controlada por capital italoargentino del grupo Techint.

En el desmantelamiento de la empresa nacional, la reestructuración de Sicartsa inició con el fraccionamiento del complejo, que desembocó en la desincorporación total, y una política de reducción 
de endeudamiento. El conjunto se dividiría en cuatro firmas: Sicartsa, que se quedaría con las instalaciones de Sicartsa I; Siderúrgica del Balsas, S. A. de C. V. (Siderbal), que recibió Sicartsa II; Servicios Minerometalúrgicos de Occidente, S. A. de C. V. (Seminosa), y Servicios Siderúrgicos Integrados, S. A. de C. V. (ssisa) (Martínez, 2003). El proceso de modernización implicó la reducción de la planta de trabajadores a la mitad: de casi 5000 obreros se redujo a 2500 , de acuerdo con la información proporcionada por la dirigencia seccional del Sindicato Minero. La mayoría de los despedidos fueron trabajadores de mantenimiento y servicios con perfil profesional de oficio. De la cohorte de trabajadores despedidos algunos retornaron al mundo obrero a través del modelo de subcontratación y otros como empleados en los sectores de servicios y comercio.

$\mathrm{Al}$ ser un proceso continuo, es difícil en el plano estructural que se subcontraten tareas en las áreas de producción de acero, lo que perfiló el tipo de despido: por un lado los obreros de oficios — paileros, tuberos, electricistas, mecánicos, soldadores y montadores-, y por otro el conjunto de trabajadores que realizaban tareas de mantenimiento de baja calificación. Según la propia dirigencia seccional del Sindicato Minero, la escolaridad del total de despedidos no rebasaba el nivel de secundaria y las edades fluctuaban entre los 30 y los 50 años. Los sobrevivientes al despido fueron básicamente los trabajadores del área de producción, lo que no significó una renovación de personal en esta área, como ocurrió parcialmente en las tareas de mantenimiento.

La nueva gestión de la mano de obra denominada "subcontratación" fue determinante en las trayectorias identitarias de los siderúrgicos. En este nuevo modelo laboral las historias laborales de los trabajadores cobran sentido. Para un sector de los despedidos implicó la posibilidad del retorno a la industria en condiciones desfavorables de protección social y de condiciones de trabajo. Para otro sector representó una salida definitiva del mundo industrial. Para los que sobrevivieron al despido significó desarrollar una vida laboral bajo nuevas reglas basadas en el principio de flexibilización laboral. El retorno como obreros, por medio del subcontrato, supuso una movilidad social descendente de los despedidos, fue una caída en el estatus que se mantenía debido a las características del empleo que se basaba en ingresos fijos, seguridad social y salarios por encima de la media obrera nacional. Además, ingresar a la fábrica a través de subcontrato representó emplearse en condiciones de menor resistencia y mayor docilidad a la movilidad laboral que sus contrapartes sindicalizados. Para los sobrevivientes del despido la nueva gestión de mano de obra ejerció una fuerte presión para ceder a la unilateralidad empresarial en las relaciones laborales.

\section{Cambios y continuidades en la identidad obrera de enclave}

De la inflexión en el enclave siderúrgico surgieron nuevas categorías de trabajadores: los sobrevivientes de los procesos de modernización y los exsiderúrgicos. Trabajadores que han realizado enormes esfuerzos por mantener una cultura y una identidad obreras en medio de procesos sociales, culturales e institucionales generados por los cambios en la estructura industrial y ocupacional del país, así como por la racionalidad organizativa de las empresas. En lo que resta del presente estudio se dará razón del complejo y ambiguo proceso de la identidad obrera en el contexto de la fragmentación a la que fue sometida con la reestructuración industrial. La tesis que se sostiene pone en duda la pérdida de las identidades de los trabajadores. Con la reestructuración y privatización de Sicartsa se consolidó un mercado de trabajo desigual en la planta: uno directamente ligado a la empresa, estable y con fuerte protección sindical; otro vinculado al subcontratismo con un componente de inestabilidad, especializado en la 


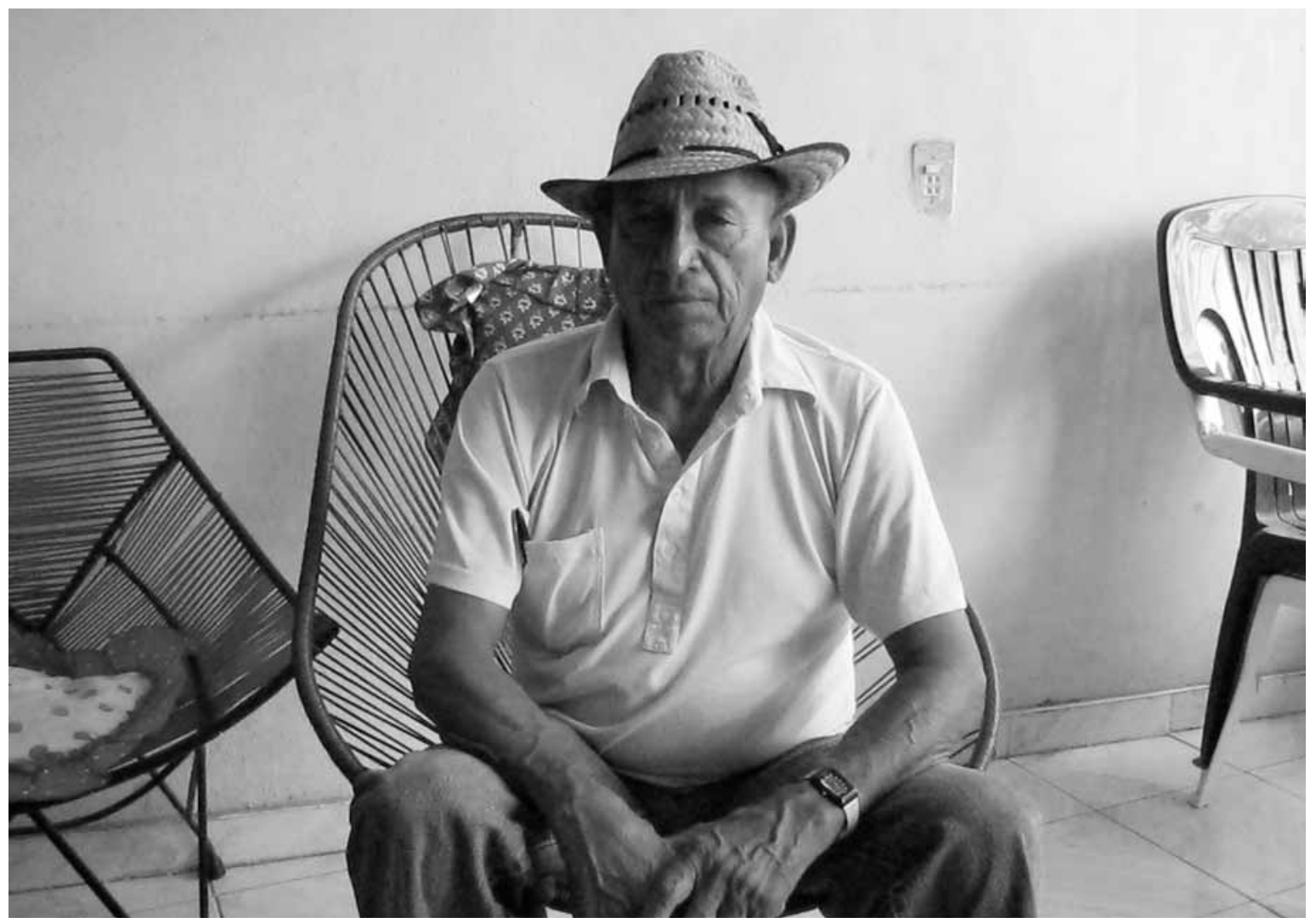

Eleocadio Martinez Silva Exobrero Fidel Mena.

construcción y en los servicios y subordinado a la lógica de la empresa siderúrgica.

En este mercado de trabajo se profundizó la fragmentación de los obreros siderúrgicos. La fragmentación no sólo se presenta entre sindicalizados y subcontratados. Entre los primeros se observan rasgos diferenciados por la división de Sicartsa en cuatro empresas. Otro factor de diferenciación en este grupo obrero es la generación: los sobrevivientes al despido, herederos de una cultura obrera, y la nueva generación. La fragmentación obrera se acentuó con la conformación de los exobreros, aquellos que no retornaron al trabajo siderúrgico. La composición obrera se complejizó más debido a que los estibadores que trabajan para una empresa filial de Mittal mantienen una lucha por formar parte del Sindicato Minero. Tal iniciativa es apoyada por el sindicato con la idea de aumentar la membresía gremial. ${ }^{7} \mathrm{La}$ fragmentación de la clase obrera, sin embargo, no derivó en la destrucción de identidades. Entre los sobrevivientes se mantuvo por la permanencia del sindicato y su acción colectiva. En los despedidos la identidad continuó por la

7 La relación de los estibadores con la siderúrgica tiene una historia de décadas. Afiliados a la CROM por medio del Sindicato de Estibadores, tuvieron una relación directa con Sicartsa. Después fue indirecta a través de Servicios Portuarios, momento en el que los estibadores elaboraron un contrato colectivo muy ventajoso. Con las privatizaciones y con un contrato colectivo mutilado, los estibadores se contratan con una empresa filial de Mittal. 
conservación del barrio y el enclave, espacios de su socialización primaria.

De lo hasta aquí descrito me pregunto acerca de lo que vincula y diferencia identitariamente al conjunto de los trabajadores que comparten un mismo espacio laboral y social, así como un mismo pasado. Se toma en cuenta que los obreros que comparten el espacio siderúrgico, incluso los exobreros, no son grupos cerrados, ya que cada uno se relaciona en redes interpersonales e interactúa dentro y fuera del espacio fabril y a nivel de relaciones grupales. Sin embargo, las diferencias están lejos de desaparecer debido a las diferencias en el poder de ingreso y la estabilidad en el empleo, lo que erosiona la posibilidad de crear una comunidad de obreros, no es que no puedan compartir valores comunes, aunque también hay oposiciones económicas, culturales y políticas que dificultan una comunión. Reconstruyamos este proceso.

\section{Los sobrevivientes y los desheredados del proceso de reestructuración}

Los trabajadores que sobrevivieron al despido continúan compartiendo características en cuanto a su composición: grados de calificación, obreros con experiencia industrial o que pueden adquirir rápidamente las habilidades. También tienen un componente heterogéneo en función de la estratificación dentro de la estructura ocupacional de la planta siderúrgica. ${ }^{8}$ La división de Sicartsa implicó una mayor fragmentación en términos de identidades laborales de los siderúrgicos: en Sicartsa I se concentra el mayor porcentaje de los sobrevivientes del proceso de reestructuración y privatización. Son los obreros de mayor antigüedad y, por tanto, los más politizados y participativos en la vida sindical. ${ }^{9}$ En términos de prestaciones, son los que reciben el mejor bono de productividad y utilidades. Los obreros de Sicartsa II son la nueva generación de obreros siderúrgicos, se incorporaron a la empresa después del proceso de privatización. La media estudió la preparatoria, es decir, tiene mayor nivel de escolaridad que sus camaradas de Sicartsa I.

A pesar de esta fragmentación, los sobrevivientes al despido comparten una "identidad genérica" en cuanto a un "nosotros" los siderúrgicos. Se identifican por el hecho de trabajar directamente en la planta, percibir los salarios y las utilidades más altos de la región y por pertenecer a un sindicato:

Todos pertenecemos al gremio minero, no importa el área donde estés. Si en planos [planta de fabricación de planchón] tienen problemas [un horno eléctrico está descompuesto, la empresa no quiere arreglarlo y es un peligro para el trabajador], lo llevamos a votación y acordamos parar hasta que lo arregle (entrevista con obrero).

La sección sindical sigue desempeñando un papel central en la cohesión de los trabajadores sindicalizados y subcontratados: ha limitado la unilateralidad empresarial producto de los cambios en los contratos colectivos, impone límites a la política de flexibilización y subcontratación, y continúa negociando de manera ventajosa en las revisiones del Contrato Colectivo de Trabajo..$^{10}$ La continuidad del sindicato y su acción han estimulado la identificación de los trabajadores como colectivo: "somos sindicalizados”, más allá de si la fábrica es estatal o privada. El sindicato también establece los alcances de las empresas subcontratistas en la gestión del personal

El componente heterogéneo de los siderúrgicos se profundizó a partir de la fragmentación de Sicartsa en las cuatro empresas: Sicartsa I, formas largas; Sicartsa II, formas planas; La Mina, mineral ferroso, y Servicios, mantenimiento, lo que significó cambios en la identidad del sector siderúrgico obrero.

9 Todos los secretarios generales y del trabajo han salido de esta planta.

10 Por ejemplo, en 2009 la empresa otorgó 8\% de incremento directo al salario base más $2 \%$ en prestaciones después de un mes de huelga (Eseverri, 2009). 
obrero subcontratado, ya que tiene la facultad de vetar ante Mittal a la empresa contratista que violente los derechos laborales:

Poco a poco se han podido recuperar muchas ventajas que teníamos cuando la empresa era Sicartsa, la flexibilización de los puestos de trabajo en muchos casos quedó solamente en el papel, también se han recuperado muchos trabajos de planta que se perdieron cuando se dio la privatización (entrevista con líder sindical).

Esta "identidad genérica" también se construye a través de un "ellos": los trabajadores de las empresas subcontratistas que laboran en la planta. "Ellos" realizan las tareas más penosas y pesadas, no tienen sindicato que los defienda de los atropellos de los contratistas ni un trabajo estable, tuvieron que regresar al trabajo obrero por no haber cuidado su indemnización al ser despedidos de la empresa:

Ellos no tienen los cuidados de seguridad para el trabajo [mascarillas, lentes, guantes]. La empresa hace contratos con gente de afuera, pero uno tiene que ayudarles para eso de la seguridad. Los ponen en los trabajos más pesados. Son muchas friegas para ellos. El contratista los discrimina. Nosotros en nuestra oficina tenemos nuestro micro, aire acondicionado... Ellos ven eso, se sienten incómodos. Los trabajadores de las empresas contratistas tienen sus propios espacios, pero hay compañerismo, no los discriminamos (entrevista con obrero).

Como "identidad concreta", entre los trabajadores sindicalizados se construyen diferencias. Los de la planta de Sicartsa I son los más "grillos", los que se "agandallan" los puestos sindicales, las prestaciones y las utilidades. Así lo refiere un obrero:

Desde siempre los principales puestos sindicales, como el de secretario general, sale de la planta de largos [fabricación de varilla y alambrón], a nosotros los de planos [fabricación de planchón] nos dejan las carteras de menor importancia. Allá es donde están los principales grupos sindicales, los principales dirigentes. También se llevan la mayor parte de las utilidades, ya que la empresa las reparte en función a la producción de productos terminados, lo cual solamente es posible en la planta de largos (entrevista con obrero).

A 20 años de los despidos masivos, en Sicartsa está ocurriendo una transición generacional. Los sobrevivientes de los procesos de privatización están en el trayecto de la jubilación y una nueva generación de obreros se está consolidando. Si bien ambos grupos han sido sometidos a la cultura de la calidad total para admitir y hacer suyos los principios de calidad y productividad propuestos por la empresa, los sobrevivientes a los despidos son los herederos de una cultura del trabajo construida en tiempos de la empresa nacional, la cual se sigue haciendo presente en la vida cotidiana en el trabajo. La joven clase obrera, al tener pocos referentes acerca de lo que fue la cultura obrera en Sicartsa, tiende a pensar de manera diferente su vínculo con el trabajo y el sindicato. Aunque predomina un marcado "nosotros" - mineros, siderúrgicos, sindicalizados - vinculante, también hay un "ellos" que los diferencia:

Como que los obreros antiguos se quedaron con las mañas de trabajo del tiempo de Sicartsa, siguen haciendo como que trabajan, andan buscando el límite de faltas por mes, siguen viendo al sindicato como el protector de su flojera. Uno que no está maleado busca que a la empresa le vaya bien, que el trabajo que uno hace se haga bien, así todos salimos ganando (entrevista con trabajador joven).

Entre los trabajadores de la subcontratación se presentan rasgos homogéneos debido a su formación profesional de oficio y heterogéneos en virtud de 
su relación laboral, unos trabajan de manera permanente en la planta por los contratos anuales que ofrecen algunas de las empresas, otros se emplean por temporadas bajo la modalidad de "paros". ${ }^{11}$ En la actualidad, el conjunto de trabajadores de las empresas subcontratistas que prestan sus servicios a la siderúrgica llegan a representar la mitad del total de la planta. Un porcentaje de ellos son exempleados - los "desheredados" - que reingresaron a la planta a través de las empresas constructoras que dan servicio y mantenimiento a la fábrica. En Mittal retornó alrededor de 40\% de los despedidos, el resto son obreros con una trayectoria laboral en las empresas constructoras, trabajadores con oficios, sin experiencia sindical y con empleos inestables.

Los salarios entre los obreros subcontratados tienen variaciones relevantes. Muchos ganan 5000 pesos mensuales, y otros llegan a percibir 20000 pesos al mes, según el oficio y las características del trabajo. Los obreros que trabajan en los "paros" tienen los mejores salarios, pero con jornadas extenuantes de 12 horas diarias de lunes a sábado y durante periodos muy cortos. Para quienes trabajan por contratos a largo plazo los salarios son los más bajos, con jornadas de ocho horas, cinco días a la semana. Este conjunto de obreros se ubica en las áreas de mantenimiento y servicios, donde predominan los trabajadores de oficio, como paileros, tuberos, soldadores, mecánicos, armadores, argoneros y ladrilleros.

Para los exempleados de la siderúrgica la reinserción al trabajo obrero significó una continuidad en el oficio. El despido no representó la pérdida de la identidad ocupacional. Sus trayectorias hablan más de un incremento de las calificaciones adquiridas, extendieron el conocimiento del oficio debido a que se les demandaba y vivieron un proceso de aprendizaje a través de compañeros trabajadores con amplias trayectorias profesionales. A estos trabajadores no se les define ni se autodefinen como siderúrgicos, mineros o sindicalizados en virtud de que no trabajan de manera directa para la siderúrgica.
Aun en el caso de los obreros que realizan tareas en el área de producción, como sucede con los de Acerería Eléctrica, están con un pie fuera y otro dentro de la planta por su adscripción a la empresa contratista y por el vínculo en las labores de producción en Mittal:

\begin{abstract}
Desde que nos reajustaron dejamos de ser sindicalizados, ahora nuestro patrón es la constructora, ya sin sindicato. La constructora es nuestro patrón, aunque trabajemos en la planta ya no somos parte de ella, eso se acabó con el reajuste (entrevista con exempleado siderúrgico).
\end{abstract}

No obstante, sus vínculos con los trabajadores sindicalizados siguen siendo fluidos. Además de compartir espacio y tareas en el piso de fábrica, los exempleados también establecen relaciones con el Sindicato Minero. La Sección Sindical 271 recibe una cuota por hora-hombre que labora en las empresas contratistas. En función de este vínculo, el sindicato se abroga el derecho de su defensa cuando se presentan abusos del contratista. La acción puede llegar a exigir a Mittal la cancelación del contrato con la empresa constructora. La acción de defensa del obrero contratista es asumida por el sindicato no como protección a sus derechos laborales, sino a sus derechos humanos: "Desde hace 10 años se ha sindicalizado a 700 obreros que trabajaban en empresas contratistas. Eran obreros que realizaban tareas y actividades que deberían de llevar a cabo trabajadores sindicalizados" (entrevista con dirigente sindical).

La acción sindical no es sólo un asunto de solidaridad obrera sino de membresía y defensa de los puestos de trabajo sindicales, "cuidar que no los desplacen". Entre estos extrabajadores no hay una

11 El "paro" es cuando los hornos necesitan reparación o reconstrucción general. 
continuidad en la identidad siderúrgico, minero, sindicalista, sino como obreros de oficio y de empresas constructoras. En sus narrativas anteponen el oficio y a la empresa contratista como la identidad que los vincula al mundo del trabajo en general y siderúrgico en lo particular: "Con el despido de la empresa, a uno solamente le sigue quedando el oficio. Es lo que nos ha sacado adelante en la industria, de no haberlo aprendido en Sicartsa andaríamos de taxistas, de comerciantes" (entrevista con exempleado siderúrgico).

La identidad de estos obreros se torna más compleja ya que sufren periodos de desempleo con frecuencia. Sin embargo, no se autorreconocen como desempleados, independientemente de la duración de los lapsos de inactividad. Esto tiene que ver con al menos tres aspectos: 1) el orgullo profesional: estos obreros muestran rechazo hacia otras actividades laborales que no tengan que ver con los oficios y se niegan a devaluar su trabajo cuando les ofrecen salarios inferiores a los que ellos piensan que es lo justo o a lo que están acostumbrados, prefieren esperar una buena oportunidad; 2) la reposición de la fuerza de trabajo: dada la precariedad del trabajo que en muchas ocasiones exige jornadas de 12 horas diarias deciden pausar su trabajo con las empresas contratistas, y 3) ven su situación de inactividad como un momento transitorio, por la gran demanda del trabajo de oficio:

La gente que nos ve sin trabajar piensa que somos flojos, que no nos gusta trabajar, no entienden que tenemos nuestro oficio, es el que nos defiende en el trabajo. Según nos convenga sabemos cuándo y con quién contratarnos. Un buen contrato por tres meses te da para vivir, sin necesidad de andarte matando todo el año con bajos salarios (entrevista a trabajador de oficio).

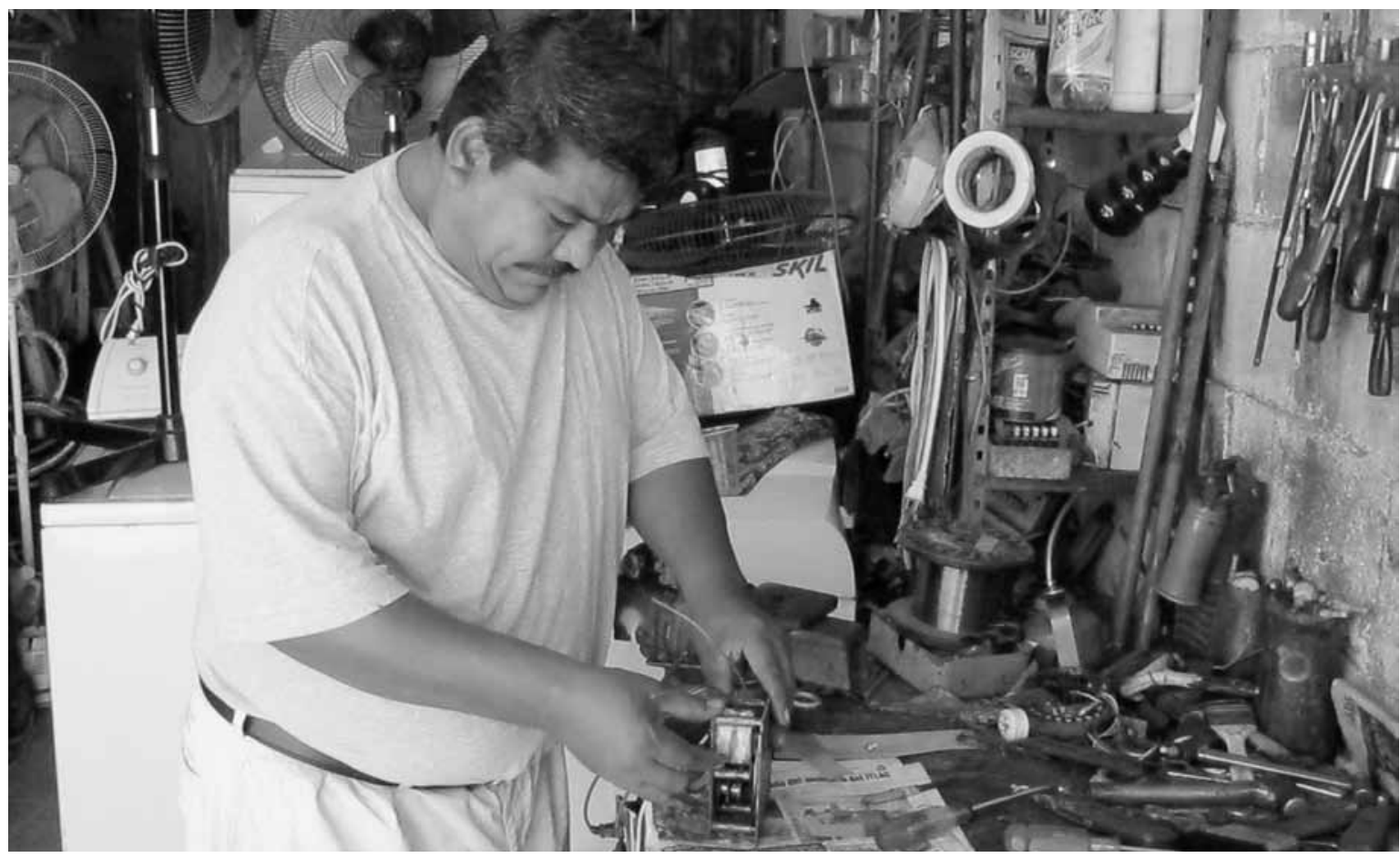

Eleocadio Martínez Silva Exobrero Jesús Ramos. 
Estos trabajadores comparten una identidad genérica en cuanto a un "nosotros", los obreros de las constructoras. Se identifican por un mejor conocimiento del oficio que los sindicalizados, por hacer mejor el trabajo, por su fortaleza física debido a las largas jornadas de trabajo y las malas condiciones climáticas:

Lo que se aprende en las empresas constructoras no tiene comparación con lo que se aprende estando sindicalizado. Por fuera aprendemos a desarrollar todo el oficio, ya sea de soldador, de pailero, de tubero, de mecánico, ya que hacemos trabajos de construcción. Los sindicalizados solamente aprenden a hacer composturas, a reparar, no a construir (entrevista con obrero).

Como identidad concreta, entre estos obreros se construyen diferencias. Los exempleados siderúrgicos son vistos por los trabajadores de las constructoras como menos expertos en los oficios, en virtud de una supuesta mala formación profesional cuando pertenecieron a la empresa siderúrgica:

Cuando los despidieron andaban buscando trabajo en las constructoras, tuvieron muchos problemas ya que no podían desempeñar el oficio al 100\% debido a que no estaban acostumbrados a trabajar en la construcción, solamente realizaban pequeños trabajos de soldadura o pailería, no conocían todo el equipo y medidas del oficio, tuvieron que aprender poco a poco (entrevista con obrero).

El "ellos" se define frente a los trabajadores de planta y las empresas constructoras, sus patrones. Los sindicalizados son aquellos a quienes no les gusta hacer los trabajos pesados y penosos, con menor calificación del oficio y que tienen un trabajo estable y un sindicato que los protege. Las constructoras explotan a los trabajadores, hacen trabajar al obrero largas jornadas sin prestaciones ni seguridad social, "los rentan" a la empresa:
La verdad que uno se siente diferente, ya nada es igual, uno es el que hace los trabajos más peligrosos, a veces no tenemos todo el equipo de trabajo y de seguridad. Ya no tienes trabajo todo el año, en ocasiones solamente por medio año. Si te enfermas, se te complica la vida ya que no puedes contratarte. Uno trabaja en la planta, pero ya nada es igual (entrevista con exempleado siderúrgico).

Entre los exempleados se observa un desprendimiento de la identidad del obrero siderúrgico y la construcción de una nueva. Como señala Helen Fuchs (1998), esto sucede a través del desplazamiento de redes de amistad. Los amigos ya no son sus excompañeros sindicalizados, sino los de las compañías subcontratistas. En términos de De Gaulejac (1991), es un proceso de desplazamiento social, una dialéctica entre reproducción y cambio, ya que en todo desplazamiento de trayectorias se produce una distancia entre las posiciones objetivas y las subjetivas, entre el lugar y las relaciones en el lugar. Esta distancia es un espacio libre donde el individuo puede trabajar en ajuste-desajuste, identificación-desidentificación, territorialización-desterritorialización, idealizacióndesidealización. Por tanto, el desplazamiento social entraña una serie de conflictos afectivos, ideológicos, culturales, relacionales y políticos que se cristalizan en las relaciones del individuo en su lugar y su identidad.

\section{Los exobreros}

En los procesos de reestructuración y privatización del sector siderúrgico se construyó una nueva categoría de trabajadores en el enclave de Lázaro Cárdenas: los exobreros. A diferencia de los trabajadores de oficio que han llevado a cabo esfuerzos y acciones tendientes a la reafirmación identitaria en contextos fabriles, un sector muy amplio de exempleados siderúrgicos han estado inmersos en un proceso contradictorio de "dejar de ser obreros". Los exobreros 
no tuvieron una calificación de oficio, estaban en edad de jubilación o en posibilidades de acceder a una pensión, o deseaban salir de la disciplina del trabajo industrial. En general, aceptaron trabajos de baja calificación en el mercado laboral o en Estados Unidos, en el sector de los servicios y el comercio. Incluso algunos se hicieron pescadores.

En los despidos en Sicartsa se presentaron dos situaciones: quienes solicitaron ser incluidos en el recorte de personal, debido a que habían visualizado nuevos horizontes laborales, y quienes no deseaban el despido. Desde la empresa, a este proceso se le asignó el eufemismo de "reajuste". Con el tiempo, este término legal se transformó en identificación y autoidentificación de los despedidos de Sicartsa. La identidad fue construida como "reajustados" o "exobreros". ${ }^{12}$ Esta figura ha sido políticamente útil para un sector de exempleados siderúrgicos que no lograron reinsertarse en el mercado de trabajo, dada la permeabilidad de las fronteras entre empleo y desempleo que existe en México. Esta figura ha sido eficaz para negociar apoyos sociales ante instancias de gobierno, lo cual ha sido posible por el reconocimiento de otros actores de la identidad del "exobrero" o "reajustado”. En el caso de Lázaro Cárdenas, los extrabajadores han constituido diversas asociaciones civiles de exobreros para enfrentar el despido y llevar a cabo la acción política.

Este autorreconocimiento y reconocimiento identitario no sólo tiene influencia en el ámbito político, también ha funcionado como mecanismo social para enfrentar los problemas de la vida diaria. Autorreconocerse y ser reconocidos como "reajustados" les ha permitido darle continuidad a su origen ocupacional y social: "trabajo como comerciante, pero soy soldador", "manejo un taxi, pero soy exsiderúrgico". Esta trayectoria identitaria contradictoria de un sector de los despedidos de Sicartsa es común entre los trabajadores mexicanos que son expulsados de la industria, dada la poca historia del proletariado nacional y debido a que el desempleo no es institucionalmente reconocido. En este proceso los despedidos hacen uso de algunos rasgos de su identidad obrera y otros la resignifican, unos logran establecer una nueva identidad y otros no, algunos están envueltos en procesos de reforzamiento y/o resignificación de sus prácticas identitarias, tanto para resistir como para acomodarse a la nueva realidad. En la nueva identidad conservan vestigios y residuos de su pasado, de manera que para estar integrados y ser individuos plenos incorporan su historia pasada a su identidad actual.

\section{Conclusión}

Las tesis de Bauman (2005) acerca de la fragmentación de las identidades causada por transformaciones en el mundo del trabajo - heterogeneidad y flexibilidad laboral - fue puesta en duda en los hallazgos empíricos de la presente investigación. Se presentaron evidencias de que la flexibilización a la que se ha sometido el sector siderúrgico en los últimos 20 años no significó necesariamente la destrucción de las identidades obreras. En cambio tuvo lugar un complicado y ambiguo proceso por medio del cual un sector de trabajadores le dio continuidad a la identidad obrera, unos dentro del espacio fabril y otros fuera de él. Si bien los sobrevivientes al despido en Sicartsa han sido sometidos a nuevas reglamentaciones y discursos laborales, y conservado el empleo de tiempo completo durante un tiempo indeterminado, protegidos por un contrato colectivo de trabajo y, sobre todo, por el Sindicato Minero. La reestructuración de la siderúrgica no implicó una desestructuración de la identidad obrera. Los empleados siderúrgicos se identifican aún como colectivo, un "nosotros" y un

12

No es lo mismo ser desempleado por decisión propia, por un mal desempeño en el trabajo o por el despido en un proceso de reestructuración de la empresa. 
"ellos" definidos, en los que el sindicato sigue ejerciendo un papel fundamental en la cohesión e identidad de los trabajadores y está lejos de desempeñar un rol de mero agente de colocación de trabajadores desempleados. Entre tanto, la experiencia de los exempleados siderúrgicos, aquellos que retornaron al trabajo por subcontrato y los que dejaron de ser obreros, refiere a una continuidad en la identidad obrera más que a su fragmentación. El hecho de que la siderúrgica no desapareciera y que el barrio y el enclave permanecieran significó para los trabajadores conservar muchas de sus costumbres, en el entendido de que son espacios de socialización para la continuidad de formas de pensar, de sentir, de ver la vida.

En estos dos espacios las asociaciones de exobreros, de jubilados y pensionados, "el movimiento por el 5\%", ${ }^{13}$ los clubes deportivos, las organizaciones populares y las asociaciones civiles sustituyeron al sindicato en la acción política y social de algunos colectivos de exempleados siderúrgicos. Como afirma Francisco Zapata (2009), las relaciones patróncliente cambiaron de sentido porque el patrón ya no era el empresario o el administrador de empresas, sino el líder social que interactúa con las autoridades municipales o con las compañías proveedoras de agua, electricidad y gas. La continuidad en las identidades obreras se explica, según el mismo autor, a partir de la existencia de un proletariado mexicano con poca experiencia industrial que no pudo generar identidades exclusivamente obreras, por lo que los trabajadores experimentaron una fragmentación en la que coexisten lo propio del mundo fabril con lo propio del mundo pre-fabril, que fue el lugar de su primera socialización. D

13 Movimiento que agrupa a cientos de obreros que demandan el pago de $5 \%$ de la venta de Sicartsa.

\section{Bibliografía}

Bauman, Zygmunt, 2005, Modernidad liquida, Fondo de Cultura Económica, Buenos Aires.

Bizberg, llán, 1982, La acción obrera en Las Truchas, El Colegio de México, México.

Dubar, Claude, 1998, Sociologie des professions, Armand Colin, París.

Dubet, François, 1989, “De la sociología de la identidad a la sociología del sujeto”, en Estudios Sociológicos, vol. VII, núm. 21, El Colegio de México, pp. 519-545.

Elder, Glen, 1985, Life Course Dynamics: Trajectories and Transitions, Cornell University Press, Ithaca.

Eseverri, José, 2009, "Atribuyen logros a Napo", en Reforma, Sección Negocios, 24 de septiembre.

Fuchs Ebaugh, Helen, 1998, Becoming an Ex. The Process of Role Exit, University of Chicago Press, Chicago.

Gaulejac, Vincent de, 1991, La névrose de clase. Trajectoire sociale et conflits d'identité, Hommes \& Groupes, París.

Giele, Janet J. y Glen H. Elder, 1998, Methods of Life Course Research, Qualitative and Quantitative Approaches, SAGE, Londres.

Goffman, Erving, 1993, La presentación de la persona en la vida cotidiana, Amorrortu, Buenos Aires.

Hiernaux-Nicolas, Daniel, 1986, "Enclave y geografía del poder en Ciudad Lázaro Cárdenas", en Jorge Padua y Alain Vanneph (coords.), Poder local, poder regional, El Colegio de México, Centro de Estudios Mexicanos y Centroamericanos, México.

Instituto Nacional de Estadística y Geografía (INEGI), 2010, Censo de Población y Vivienda 2010, Instituto Nacional de Estadística y Geografía, México.

Martínez Aparicio, Jorge, 2003, Integración regional e internacionalización del capital en Lázaro Cárdenas, Michoacán, Universidad Michoacana de San Nicolás de Hidalgo, Morelia.

Parsons, Talcott, 1968, "The Position of Identity in the General Theory of Action”, en Chad Gordon y Kenneth Gergen (eds.), The Self in Social Interaction, Wiley, Nueva York.

Reforma, 2006, "Critican salida a paro minero", Sección Negocios, 23 de agosto.

Reygadas, Luis, 1998, "Mercado y sociedad civil en la fábrica”, tesis de doctorado, Universidad Autónoma Metropolitana-Iztapalapa, México.

Zapata, Francisco, 1978, "La formación de un sistema de relaciones sociales”, en Francisco Zapata, Las Truchas: acero y sociedad en México, El Colegio de México, México. , 2009, "Hacia una sociología del desempleo", en Boletín Editorial de El Colegio de México, núm. 138, marzo-abril, pp. 20-27. 